\title{
Earthquake Risk and Vulnerability Assessment Based on Wisner and Fuzzy Analytical Hierarchy Process Models in Port Cities: Case Study of Nowshahr City, Iran
}

\author{
Hassan Kazemi ${ }^{1} \mathbb{D}$, Nabiullah Mansouri ${ }^{2} \mathbb{D}$, Ali Jozi ${ }^{3} \mathbb{D}$ \\ Date of submission: 21 Jun. 2020 Date of acceptance: 19 Nov. 2020
}

\begin{abstract}
Original Article
Abstract

INTRODUCTION: Nowshahr port city can suffer a lot of damages in case of an earthquake due to its location in seismotectonics of Alborz with high seismic hazard, proximity to the sea, and expansion on isolated sediments. Therefore, the recognition and analysis of the extent of earthquake vulnerability in different areas of this port city can reduce damages and losses. This study was conducted to analyze and evaluate the earthquake risk and vulnerability and identify safe areas in the city of Nowshahr in times of earthquake.

METHODS: In this study, the earthquake risk of Nowshahr city was analyzed based on the Wisner model and the application of multi-criteria decision making (MCDM) approach using fuzzy analytic hierarchy process (FAHP). Initially, the effective criteria, sub-criteria, and indicators in the earthquake risk and vulnerability components were collected through a systematic review based on previous research, field survey, and experts' opinion, and were then screened and weighed by the Delphi method. Finally, the earthquake risk and vulnerability maps were extracted and drawn using a weighted linear combination method and fuzzy index maps related to each component.

FINDINGS: According to the findings, about 97.13\% (2,810.229 ha), 2.75\% (79.567 ha), and $0.12 \%$ (3.441 ha) of Nowshahr city were placed in the low, medium, and high-risk category.

CONCLUSION: Analysis of risk maps showed that the earthquake risk was higher in the central and northwestern parts of Nowshahr city than in the other areas. These areas were densely populated with heavy traffic jams, in which located high-risk facilities such as gas lines and water and sewer networks, that reminded of the necessity of planning and urgent action regarding the improvement of urban settlements and organization of urban spaces in this region.
\end{abstract}

Keywords: Earthquake; FAHP; Nowshahr Port City; Risk Assessment; Wisner Model.

How to cite this article: Kazemi $\mathrm{H}$, Mansouri N, Jozi A. Earthquake Risk and Vulnerability Assessment Based on Wisner and Fuzzy Analytical Hierarchy Process Models in Port Cities: Case Study of Nowshahr City, Iran. Sci J Rescue Relief 2020; 12(4): 298-10.

\section{Introduction}

$\mathrm{N}$ atural disasters are the existing and possible reality of the inseparable elements of the natural system that directly and indirectly affect the spatial-physical and socio-economic interactions of the city and are considered an integral part of human life. Such phenomena are following an increasing trend in number and diversity due to the destructive activities on the environment; therefore, they are regarded as a major challenge to achieve sustainable development of societies (1). A crisis occurs when the effects of danger on the vulnerable population are apparent and cause

1- PhD student of Environmental Management, Faculty of Natural Resources and Environment, Islamic Azad University, Science and Research Branch, Tehran, Iran

2- PhD, Department of Environmental Engineering, Faculty of Natural Resources and Environment, Islamic Azad University, Science and Research Branch, Tehran, Iran

3- PhD, Department of Environment, Islamic Azad University, North Branch, Tehran, Iran

Correspondence to: Nabiullah Mansouri, Email: Nmansouri@gmail.com 
damage, loss, and disruption (2). The movement of the plates relative to each other or the creation of new fractures in an area can create an earthquake that has variable destructive power depending on the amount of energy released (3).

Earthquakes are considered uncontrollable phenomena (4). Countries with high rates of urban population growth and physical development are most at risk than other ones (5). The majority of harmful effects of earthquakes are caused due to the establishment and development of urban patterns on fault zones. The formation of urban areas, along with human reckless interventions in the fault area would cause a human catastrophe with the occurrence of an earthquake (6).

Certain characteristics and components are examined regarding the crisis and risk assessment in cities. In this respect, if a location such as a port is considered a fundamental factor for the establishment of housing and employment, the question that arises is 'How this port can be effective on urban crisis and risk in the framework of its activities' (7). Multi-purpose systems, such as a geographic information system (GIS), have allowed crisis managers to employ them in determining the risk of different areas and simulating and managing resources and facilities in times of natural disasters (8).

\section{Importance and necessity of research}

Considering what was mentioned above and the significance of the earthquake phenomenon and its impact on a port city, it is necessary to provide optimal and effective measures to minimize the effects of these events. Such a purpose can be accomplished through conducting various studies, modeling the urban risk and vulnerability assessment, and predicting the effective factors in earthquake crisis management in these areas. Accordingly, the three indicators of identification, analysis, and evaluation of potential crisis are among the important indicators of crisis management.

This study aimed to analyze and evaluate the earthquake risk and vulnerability to this phenomenon and identify safe areas in Nowshahr city, Mazandaran Province, Iran, in earthquake incidence. The study area was analyzed based on the Wisner model and utilizing the multi-criteria decision making (MCDM) approach. Therefore, the main axes of this study included selecting effective criteria and indicators, preparing digital layers of factors, determining the relative and final weight, overlapping layers, and preparing vulnerability and hazard maps to determine the boundaries of areas where involve the highest risk of earthquakes and vulnerabilities.

Numerous studies have been conducted inside and outside of Iran to analyze and measure the risk of earthquake incidence and identify safe areas in times of earthquake occurrence. For instance, Abedini and Sarmasti (2017) performed a study that aimed to evaluate the vulnerability coefficient of Tabriz metropolis, Iran, against earthquakes by applying the weighted overlay model and using natural and human criteria. Moreover, they assessed human casualties and damage to buildings in times of earthquake using geographic information system (GIS) analytical facilities and presentation of the average-intensity earthquake scenario (9). Lantada et al. (2009) modeled the vulnerability of Barcelona City, Spain, using the risk_ue method (10).

Pour Mohammadi and Karami in 2014, investigated the risk assessment of municipal zones 1 and 5 of Tabriz city by considering the nature of the earthquake and its relationship with four factors of population density, building density, quality of buildings, and type of materials. Finally, the relationship between seismic vulnerability and mentioned factors was evaluated and modeled using a GIS system (11). Shamaei et al. examined and measured the harmful factors in municipal zone 1 of Tehran, Iran, using GIS. They rated the most important factors aggravating damages in zone 1 of Tehran in descending order as follows: distance from faults, land slope, proximity to incompatible landuses, building age, population density, lack of access to open urban spaces, and unsuitable areas of land-uses (12).

Tavakoli and Ashtiani (2019) prepared the seismic zoning map for Iran entirely based on isoacceleration contours, which revealed that Nowshahr port is located in a high-risk area. To prepare such a map, they used the probabilistic risk assessment method, historical earthquakes, geological information, seismotectonics, active faults, and seismic source model and considered 20 seismic zones in Iran (13).

Nowshahr city is located near the Caspian fault and the activity of faults, and the lateral structural lineaments in this region are indicative of a highly seismic zone, in which destructive earthquakes 

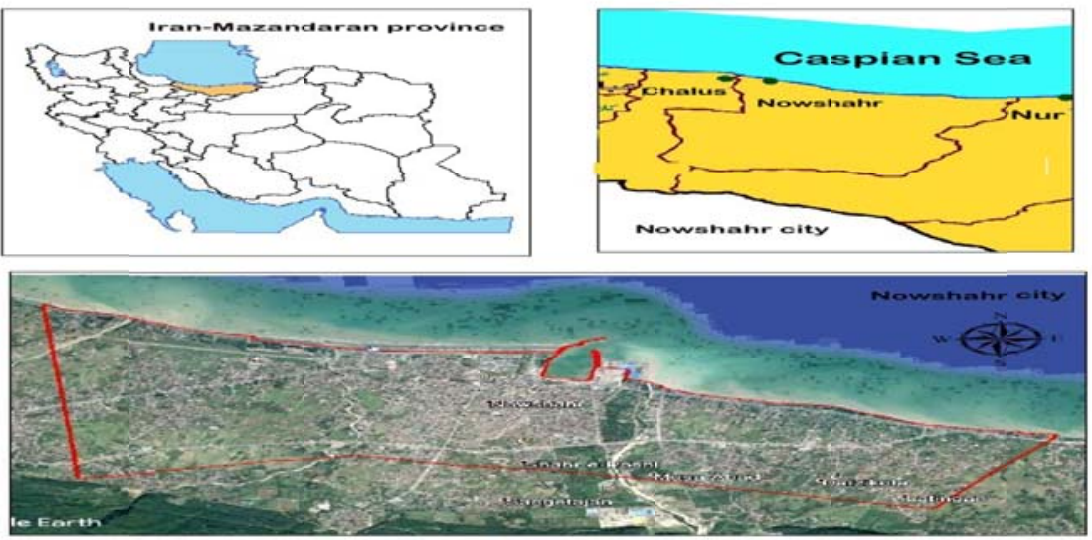

Figure 1. Study area

can occur at any possible time. Moreover, due to fact that Nowshahr city is placed in a coastal, touristic, and commercial area and the seismic potential of the Caspian fault, as well as the need for seismic risk assessment of Nowshahr city, this city was selected to be investigated and its vulnerability zoning to earthquake be determined.

Study region

The present study was conducted in Mazandaran province, Nowshahr city, and in the geographical range of $2506 / 539798$ to $5321 /$ 550348 east longitude and 9935/4052782 to $2508 / 4059017$ north latitude in the alluvial plain of Mashlek, Gerdkol, and Korkor Rivers, Nowshahr city (Figure 1).

The elevation from the sea level of Nowshahr city is 5-25 meters and it has a very low slope from south to north. The city is located on a relatively thick alluvial structure. The average annual, minimum, and maximum temperatures in this city are $15.8^{\circ} \mathrm{C}, 4.9^{\circ} \mathrm{C}$, and $29.4^{\circ} \mathrm{C}$, respectively. Furthermore, the average annual rainfall in this city is estimated at $1,280.5 \mathrm{~mm}$. The average relative humidity in the city of Nowshahr is reported to be $81.38 \%$, which is high due to its proximity to the Caspian Sea. Nowshahr city has a population of 43,378 residents with a growth rate of $0.56 \%$, which includes $33.72 \%$ of the population in this city (14). The results of natural hazard studies show that the city is located in a relatively high seismic hazard zone.

\section{Methods}

This applied research was conducted based on a descriptive-analytical approach. The following equation was used to analyze and evaluate the earthquake risk in the city of Nowshahr (15). "R = $\mathrm{H} \times \mathrm{V}^{\prime \prime}$ (Equation 1)

In this equation, $\mathrm{R}$ is the risk, $\mathrm{V}$ is the vulnerability, and $\mathrm{H}$ is the risk.

In this study, the MCDM method was used to obtain the vulnerability and earthquake risk components. Initially, the criteria and indicators affecting the two mentioned components were collected through library research and review of scientific resources related to the research topic. Afterward, the Delphi technique, as one of the most common and successful methods in MCDM, was used to screen and choose the most relevant and appropriate criteria and indicators (16). This technique is implemented based on the opinion of a group of experts and specialists in a specific field of research, which results in the selection of a set of criteria and indicators from a large group.

To conduct the research, 14 Delphi questionnaires were distributed in two rounds among specialists in location science, environmental sciences, and natural disasters with more than five years of experience in their field. The important criteria and indicators related to vulnerability and earthquake risk were determined. The English letters $\mathrm{C}$ and $\mathrm{I}$ were used to determine the criteria and indicators, respectively. Based on the results of the Delphi questionnaire, the criterion importance degree (CID) and the mean percentage of CID indicators were calculated according to equations 2 and 3 .

$$
\mathrm{CID}=\frac{\sum(\mathrm{xi} \times \mathrm{n})}{\mathrm{N}} \quad(\text { Equation } 2)
$$

In this equation, $x i$ is the primary importance degree of each criterion $(1,3,5,7$, and 9) in the questionnaire (based on these initial values, 
respondents determined the importance degree of each criterion), $\mathrm{n}$ is the number of respondents who replied to the xi of each criterion, and $\mathrm{N}$ is the number of questionnaires.

$$
\left.\mathrm{PC}=\frac{\sum \mathrm{zi}}{\mathrm{N}} \times 100 \quad \text { (Equation } 3\right)
$$

In this equation, $\mathrm{PC}$ is the average percentage of CIP and zi is the weight factor.

In the next step, the FAHP method was used to weigh the $\mathrm{C}$ and $\mathrm{I}$ values. The analytic hierarchy process was first proposed by a researcher named Saaty to model unstructured problems based on a pairwise comparison of $\mathrm{C}$ and I values and is considered a multi-criteria evaluation method in the decision-making process (17). Meanwhile, to solve the problem of ambiguity of the pairwise comparison process in the AHP method, it was proposed to add the fuzzy logic to this method (18).
The use of fuzzy theory allows the decisionmaker to make decisions although some information is incomplete, inaccessible, and qualitatively expressed and some criteria cannot be measured with each other. The Chang Extent analysis is one of the approaches applied to solve the FAHP problem (19). In this approach, triangular fuzzy numbers are used to conduct a pairwise comparison in the FAHP method.

In the present study, a questionnaire related to FAHP analysis, in which $\mathrm{C}$ and I values were identified through the Delphi method, was distributed among 14 experts to rate each of these values according to (20). Finally, with the implementation of the mentioned method, the scores of each criterion and indicator were determined in relation to their impact on the vulnerability and earthquake risk components.

A map of $\mathrm{C}$ and I vales was prepared after the

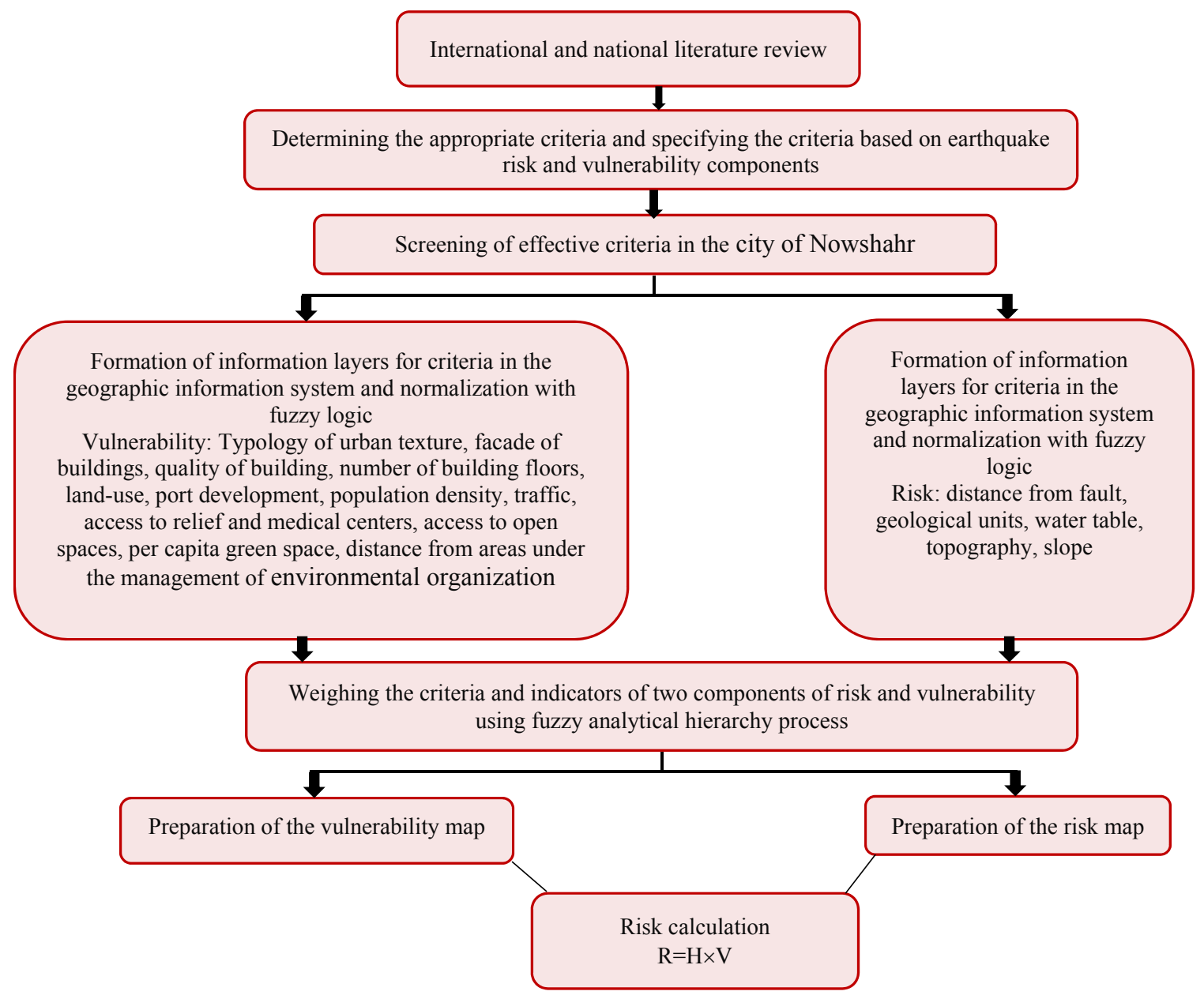

Figure 2. Procedures of performing this research 
determination of their weights. Since the developed maps had different scales regarding the size of the values, they were fuzzily standardized in the range of 1 to 0 using different fuzzy membership functions. Eventually, to prepare the final map of vulnerability and earthquake risk, relevant fuzzy maps of each component were combined using the weighted linear combination method. The mathematical equation of this method is as follows (21):

$$
W L C=\sum_{j}^{n} w_{j} r_{i j} . \sum w_{j}=1 \quad(\text { Equation 6) }
$$

In this equation, $\mathrm{w}$ is the weight obtained from the FAHP method for the map $j, r$ is the fuzzy map $\mathrm{j}$, and $\mathrm{n}$ is the number of maps used in the analysis. Finally, after obtaining the final maps of vulnerability and earthquake risk, the map of earthquake risk in Nowshahr city was prepared using Equation 1.

\section{Findings}

\section{Criteria and indicators screening}

The criteria and indicators were screened using the Delphi method and their importance degree was determined. To this end, the Delphi questionnaire containing the extracted criteria and indicators was prepared and distributed among the experts. Although these criteria were derived from numerous studies, screening and configuring them for use in a sample study created a new structure of the above criteria that bears almost no resemblance to any of the previously used criteria. The Delphi questionnaires were replied to by only 10 out of 14 experts to whom the questionnaires were sent. Subsequently, the importance degree and percentage of each criterion was determined using Delphi equations.

\section{Risk indicator screening}

In this research, five main indicators were determined for the earthquake risk component, namely distance from the fault, geological units, water table, slope, and topography, and the percentage of importance of each of them was calculated. Regarding, the indices of distance from fault and water table with $40 \%$ and $38 \%$ and topographic index with $19 \%$ received the highest and lowest percentages, respectively.

The screening process of risk indicators was accomplished by calculating the importance percentage and degree of the indicators (Figure 3). Based on the results of the screening process, the topographic index was not one of the prominent indicators for seismic hazard zoning. Therefore, the zoning process was fulfilled using the other four indicators.

\section{Screening of vulnerability criteria and indicators}

Vulnerability criteria include hazardous landuses, safety zone of urban infrastructures, human environment, and social and economic factors. The importance percentage of each of these criteria was almost in the same range. The highest importance percentage was related to the criteria of hazardous land-uses and social factors $(41 \%$ and $39 \%$, respectively), and the lowest importance percentage was reported for the human environment criteria (36\%). The findings of the vulnerability criteria screening process showed that all the five main criteria were effective and important in the zoning process and should be considered (Figure 4).

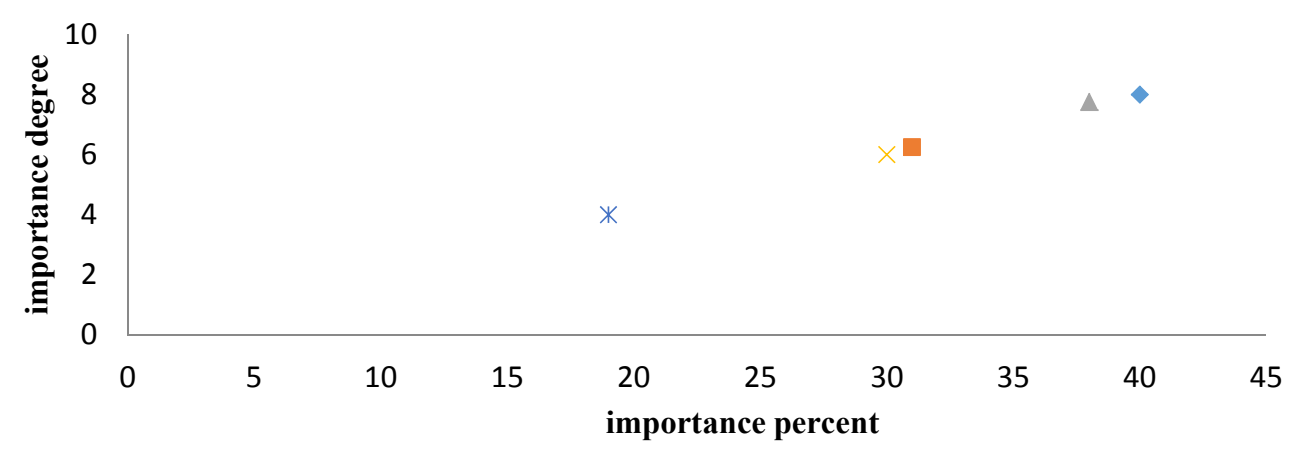

$\multimap$ Distance from fault - Geological units - Water table $\leftarrow$ Slope $*$ Topography

Figure 3. Screening based on the importance of earthquake risk indicators 


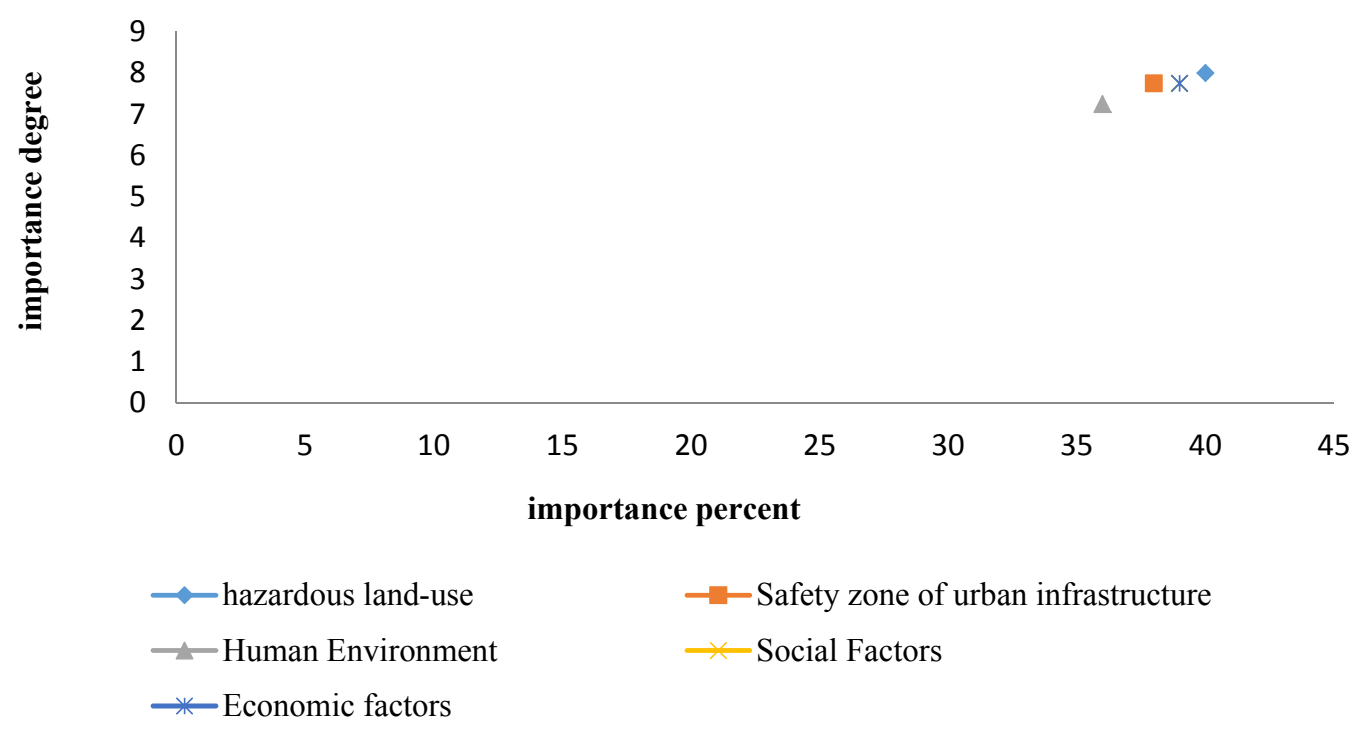

Figure 4. Screening based on the importance of seismic vulnerability criteria

Figure 5 depicts the CID for vulnerability indicators. According, the indicators of waste production, tsunami, per capita wastewater generation, and building facade were excluded from the vulnerability zoning.
Weighing by fuzzy analytical hierarchy process method

In this section, the final weight of the criteria was determined using the FAHP method. For this purpose, the weight of criteria, indicators, and

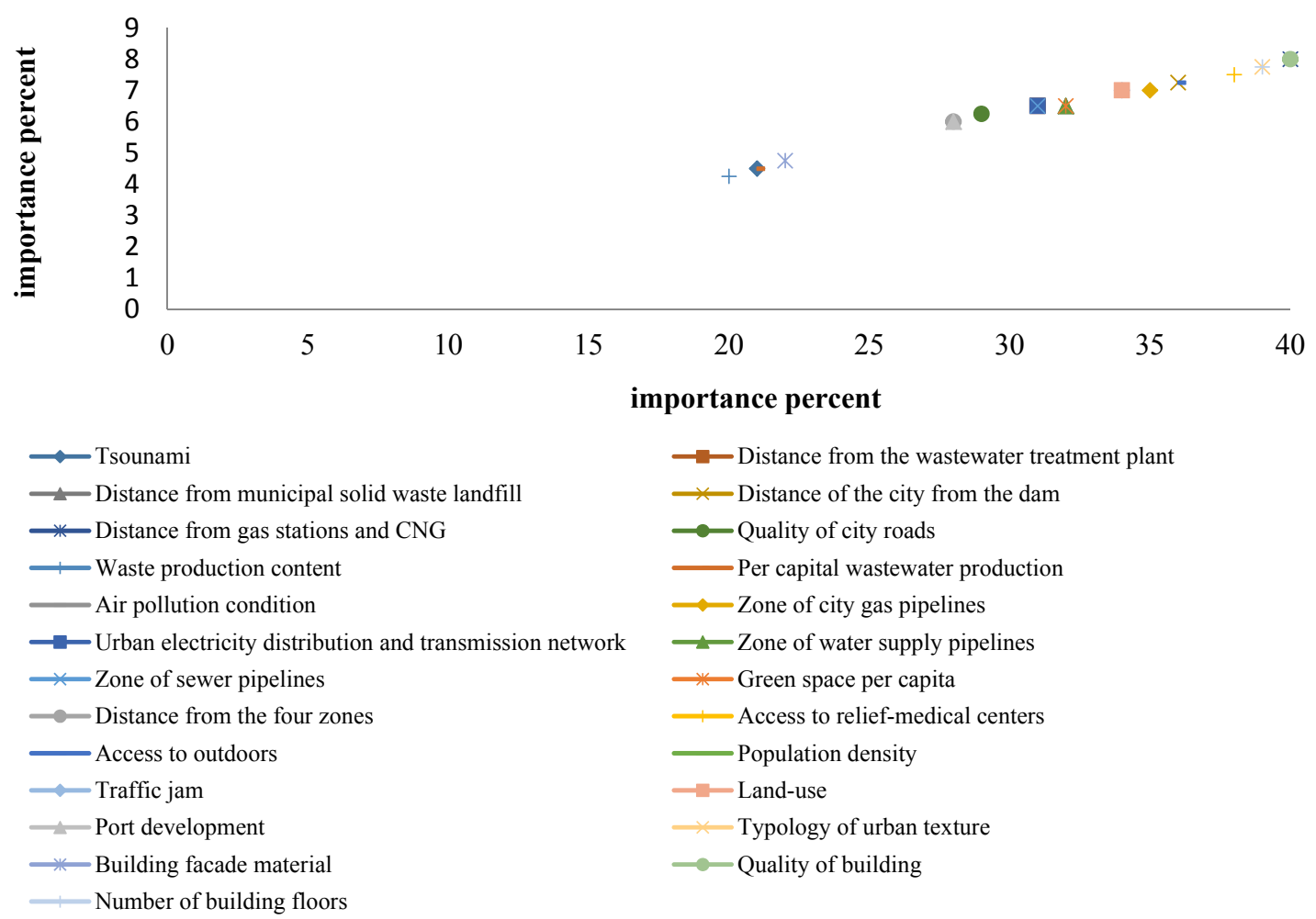

Figure 5. Screening based on the importance of seismic vulnerability indicators 
Table 1. Fuzzy comparison matrix of earthquake risk indicators

\begin{tabular}{c|ccccc} 
& Distance from the fault & Water table & Geological units & Slope & Final weight \\
\hline $\begin{array}{c}\text { Distance from the fault } \\
\text { Water table }\end{array}$ & $(1,1,1)$ & $(1,3,5)$ & $(5,7,9)$ & $(9,7,9)$ & 0.575 \\
Geological units & & $(1,1,1)$ & $(1,3,5)$ & $(5,7,9)$ & 0.263 \\
Slope & & & $(1,1,1)$ & $(1,3,5)$ & 0.109 \\
& & & & $(1,1,1)$ & 0.053 \\
\hline
\end{tabular}

compatibility rate were calculated in MATLAB software (version 2016a). The assigned weight to each criterion and indicator shows its importance in the zoning process. Consequently, the studied criteria and indicators of each crisis were weighted and prioritized using the two methods of FAHP and Delphi.

\section{Risk}

The fuzzy comparison matrix of seismic risk indicators for Nowshahr city is summarized in Table 1. Weighting results showed that the distance from the fault (I1) and slope (I4) with a weight of 0.575 and 0.053 were respectively the most and least important seismic risk indicators. The incompatibility rate of this matrix was estimated at 0.045 .

\section{Vulnerability}

It was revealed that earthquake vulnerability had five main criteria. Therefore, different comparison matrixes were formed for each criterion and indicator related to each criterion. Table 2 tabulates the comparison matrix of vulnerability criteria. The incompatibility rate of this matrix was determined at 0.07 . The results of weighting vulnerability criteria showed that the economic affairs and safety zone of urban infrastructure had the highest vulnerability to earthquakes.

After calculating the weight of seismic vulnerability criteria, the fuzzy comparison matrix and the weight of the indicators of each criterion were obtained (Table 3 ). The results of weighting showed that the distance of the city from the dam, the area of the urban gas distribution network, air pollution, population density, and the quality of building were the most important criteria. The incompatibility rate of the indicators of each of the five main criteria, namely hazardous land- uses, safety zone of urban infrastructure, human environment, social affairs, and economic affairs (urban context), was calculated at 0.072, 0.085, $0.08,0.026$, and 0.018 , respectively.

\section{Fuzzy index maps and their integration}

In this section, the results related to the preparation of fuzzy index maps of earthquake risk and vulnerability indicators in Nowshahr city were provided. These maps were fuzzyindexed using the fuzzy membership functions (Table 3).

Figure 6 shows the fuzzy-indexed maps of the four earthquake risk indicators. There is a dominant fault in the western part of Nowshahr city, where the risk of earthquakes is higher than in the other regions. In terms of the water table, the Caspian Sea coast is more prone to earthquakes than its southern part. Moreover, the risk of earthquakes is higher in areas with steep slopes.

In order to prepare an earthquake vulnerability map, fuzzy maps of vulnerability indices were prepared and then the weight of the criteria was calculated by FAHP method (criteria of hazardous land-use, Safety zone of urban infrastructure, human environment, Social factors and economic factors). Each of the weights was applied to the respective layers using GIS (Figures $7 \& 8$ ).

Subsequently, using the weighted linear combination method, the indicators and criteria of earthquake risk and vulnerability were combined and their final map was drawn (Figures $9 \& 10$ ). According to the earthquake risk map, the northern and central parts of Nowshahr city were at higher risk of earthquakes than its other parts. Additionally, the final map of earthquake vulnerability revealed that the central part of Nowshahr city, with a high density of buildings, was more vulnerable to earthquakes. 
Table 2. Fuzzy comparison matrix of seismic vulnerability criteria

\begin{tabular}{lcccccc} 
& C1 & C2 & C3 & C4 & C5 & Final weight \\
C1 & $(1,1,1)$ & $(0.2,0.33,1)$ & $(3,5,7)$ & $(1,3,5)$ & $(0.14,0.2,0.33)$ & 0.138 \\
C2 & & $(1,1,1)$ & $(5,7,9)$ & $(3,5,7)$ & $(0.2,0.33,1)$ & 0.274 \\
C3 & & $(1,1,1)$ & $(0.2,0.33,1)$ & $(0.11,0.11,0.14)$ & 0.035 \\
C4 & & & $(1,1,1)$ & $(0.11,0.14,0.2)$ & 0.068 \\
C5 & & & & $(1,1,1)$ & 0.484 \\
\hline
\end{tabular}

Criteria selected by Delphi method: C1: Hazardous land-uses, C2: Safety zone of urban infrastructure, C3: Human environment, C4: Social affairs, and C5: Economic affairs

Table 3. Type and shape of fuzzy functions used for fuzzy index map of environmental and socio-economic criteria (both types)

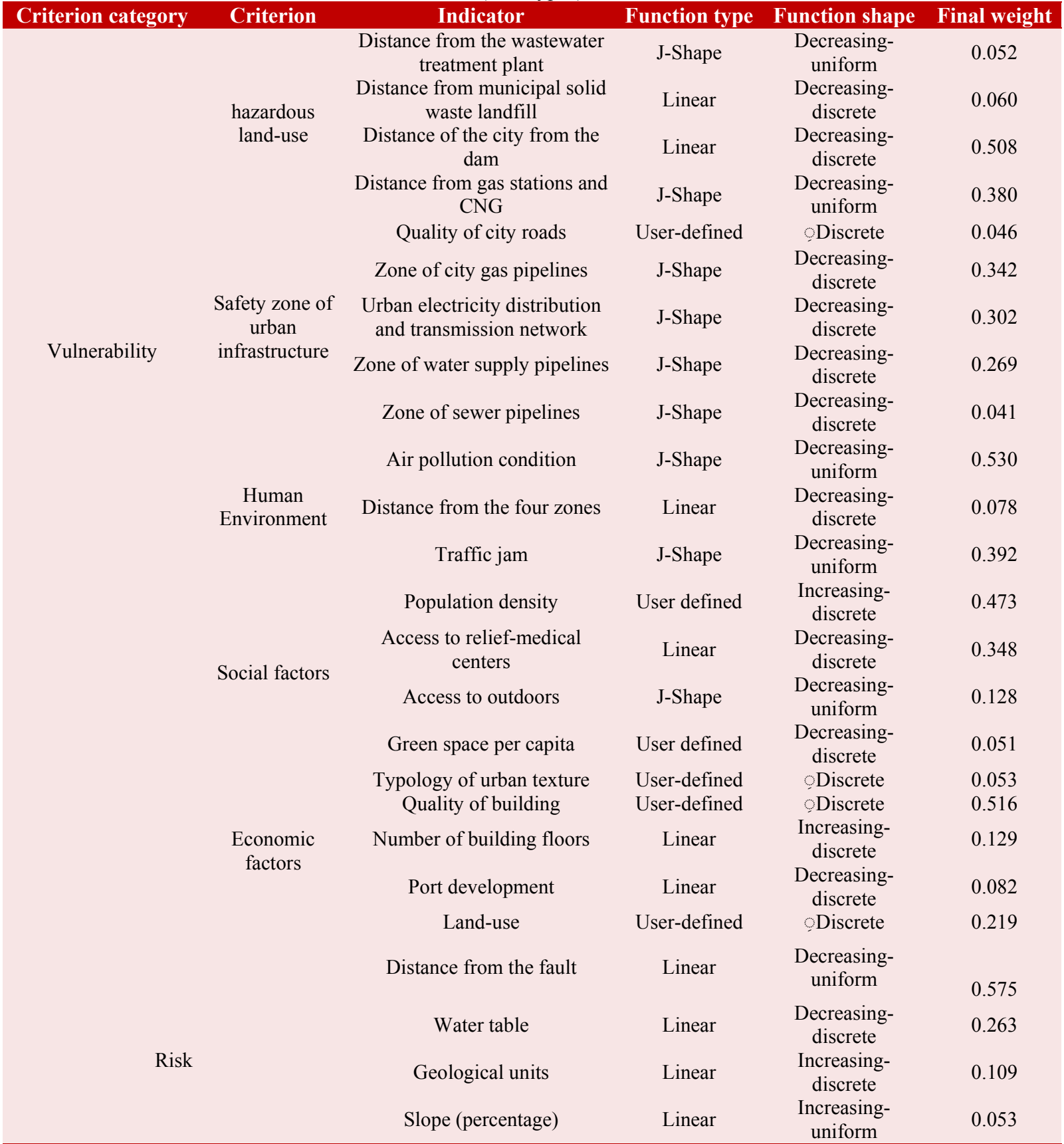



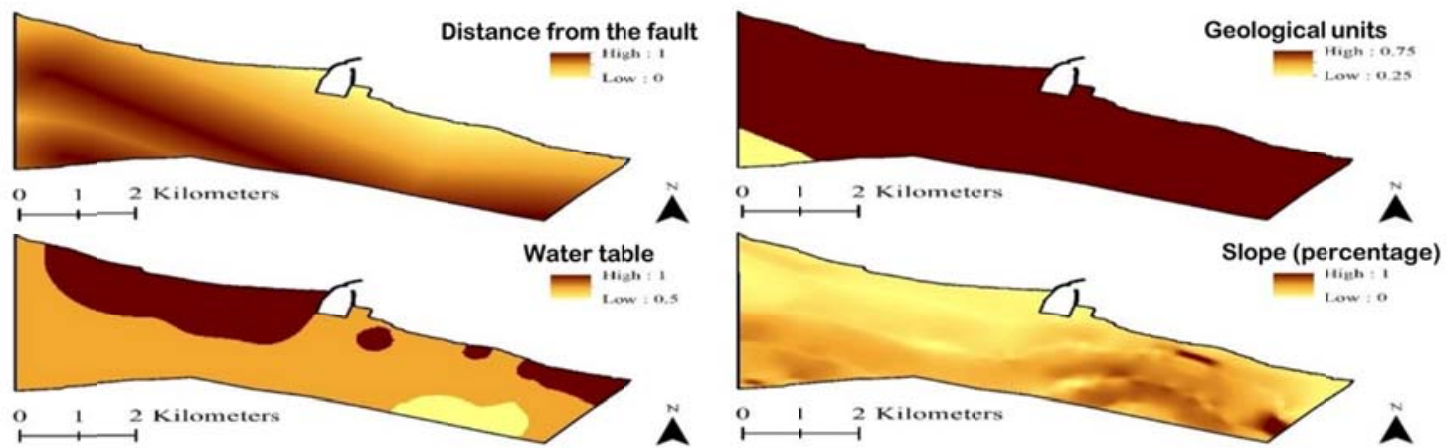

Figure 6. Fuzzy index maps of earthquake risk indicators in Nowshahr city
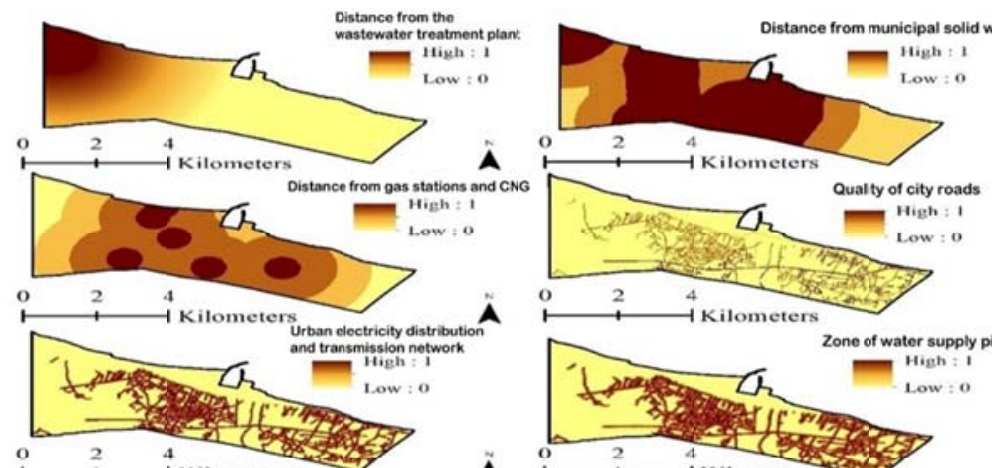

西
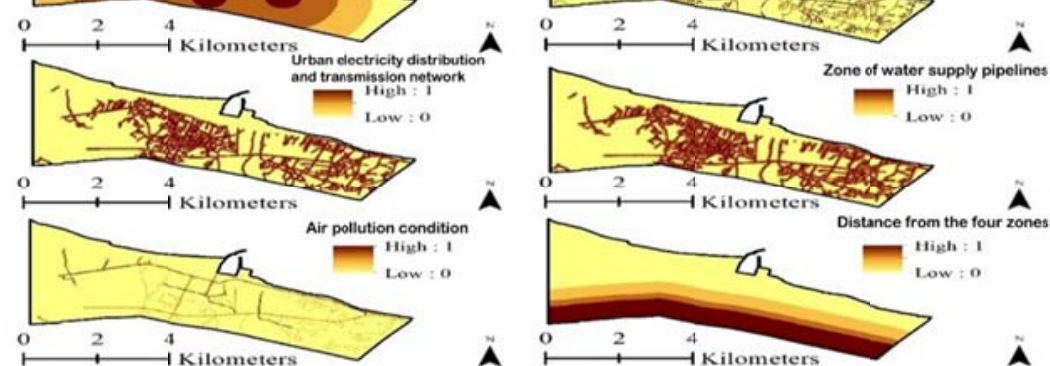

A

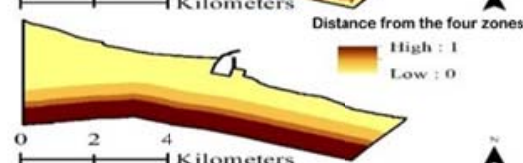

A
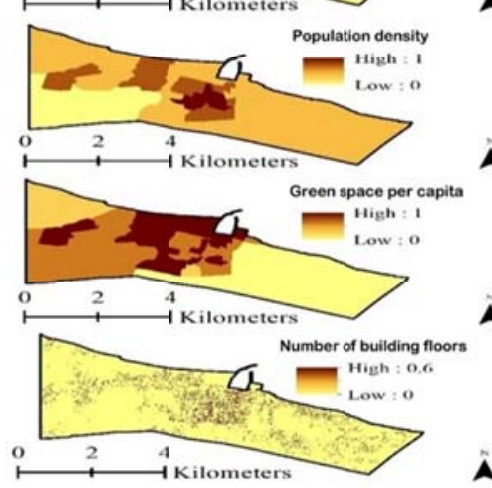

$\wedge$

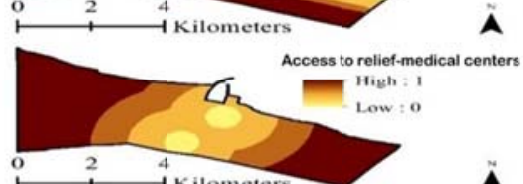

A
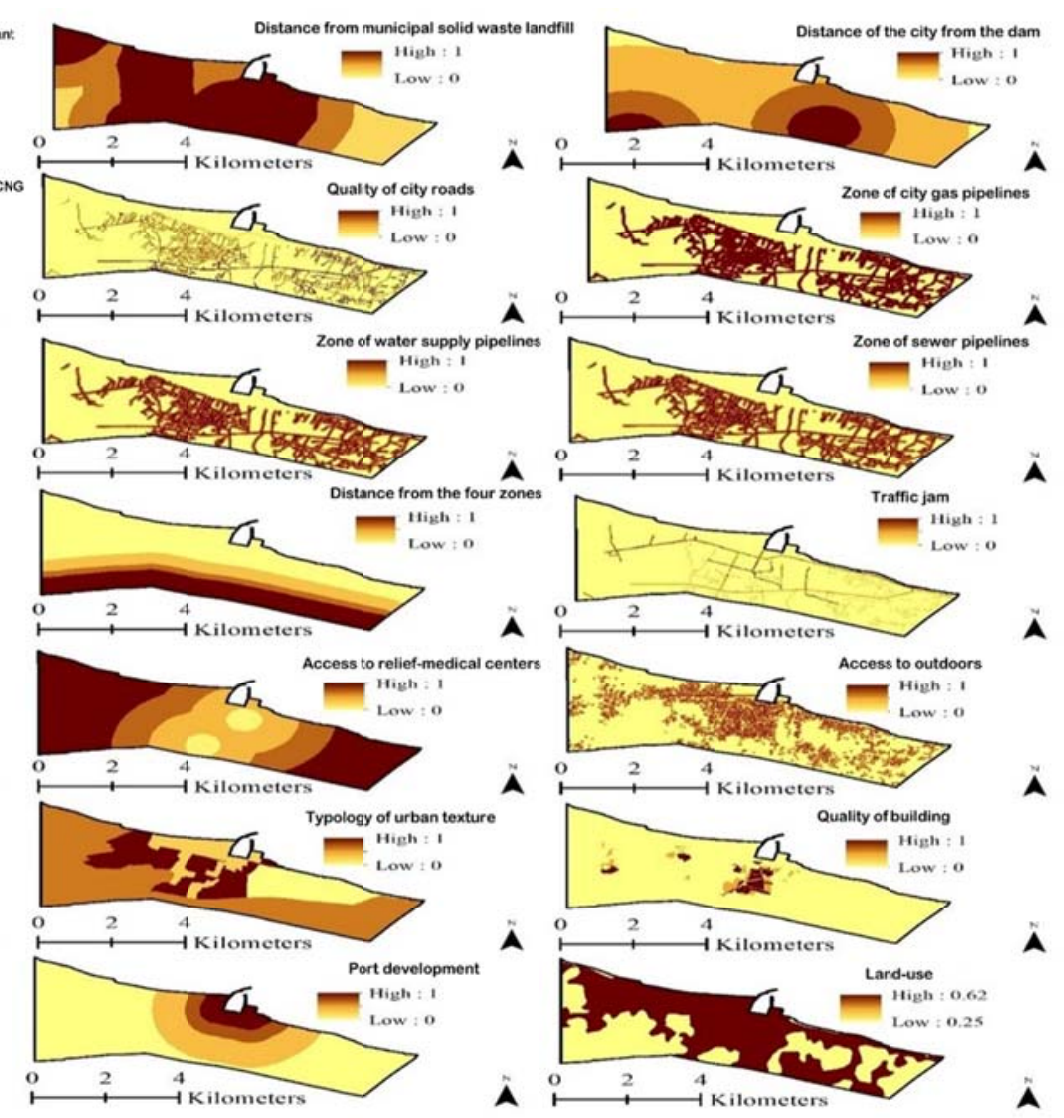

Figure 7. Fuzzy index maps of earthquake vulnerability indicators in Nowshahr city

Finally, an earthquake risk map of Nowshahr city was obtained using Equation 1 (Figure 11). According to this map, the risk of the earthquake was higher in the central and northwestern parts of Nowshahr city than in the other places. These areas are densely populated with heavy traffic jams and gas supply and sewer lines are located there. Earthquake risk fuzzy index map was converted to classified map according to the rule of $0.5-0,0.5-65$, and higher than 0.65 as low risk, medium risk, and high risk of earthquake, respectively.

\section{Discussion and Conclusion}

Risk assessment, modeling, and related management were found to be the most effective approaches to investigate the true impact of earthquakes in urban areas. It is necessary to 


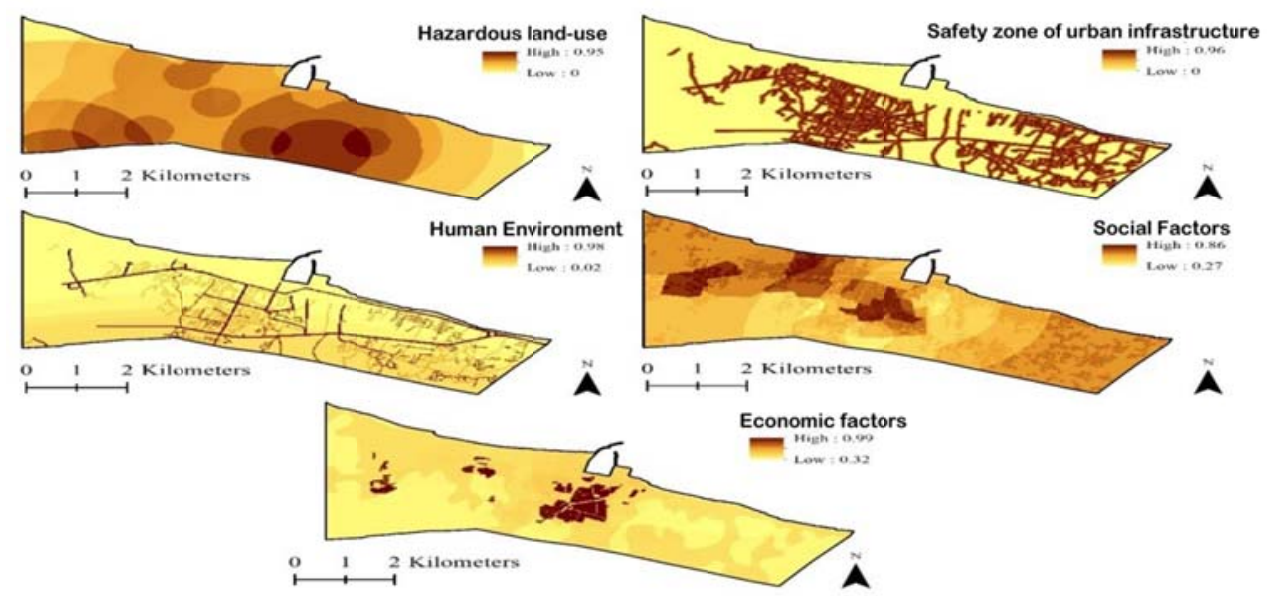

Figure 8. Fuzzy index maps of earthquake vulnerability criteria in Nowshahr city

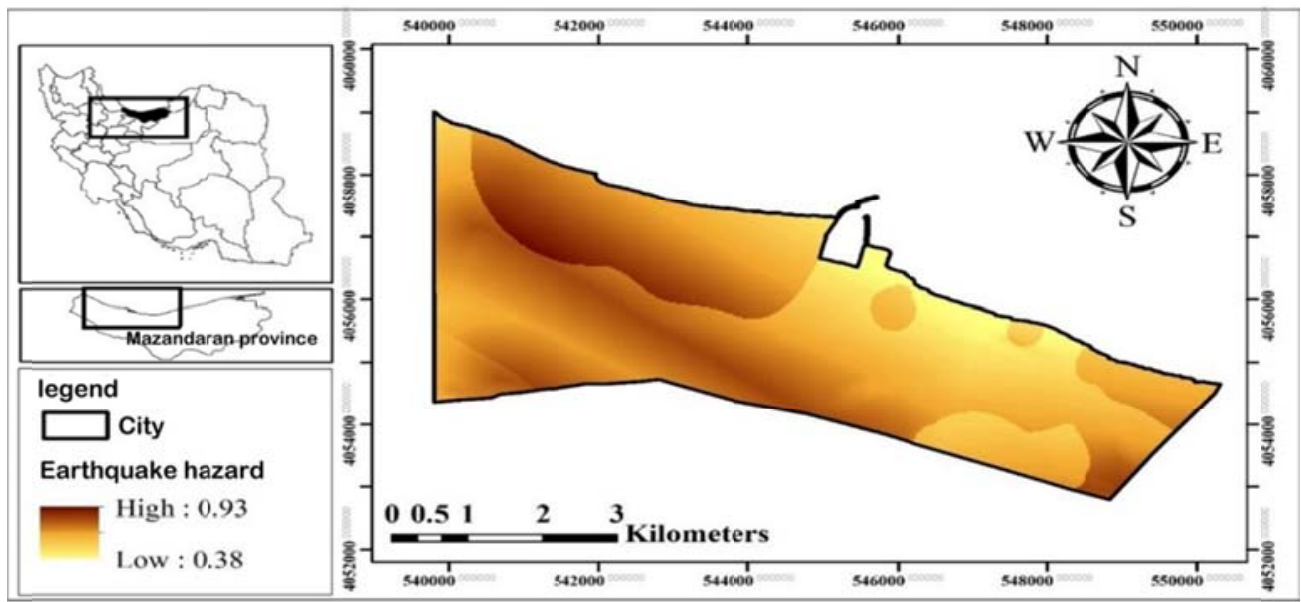

Figure 9. Final Fuzzy index map of earthquake risk in Nowshahr city

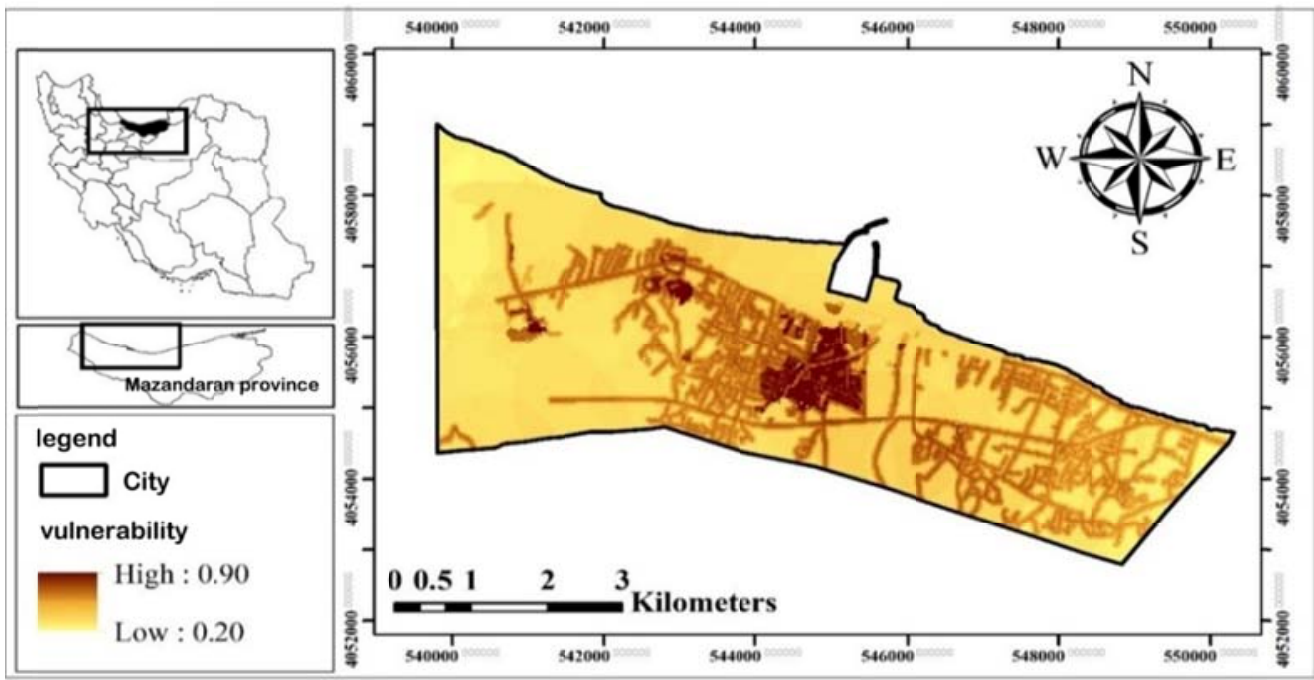

Figure 10. Final Fuzzy index map of earthquake vulnerability in Nowshahr city 


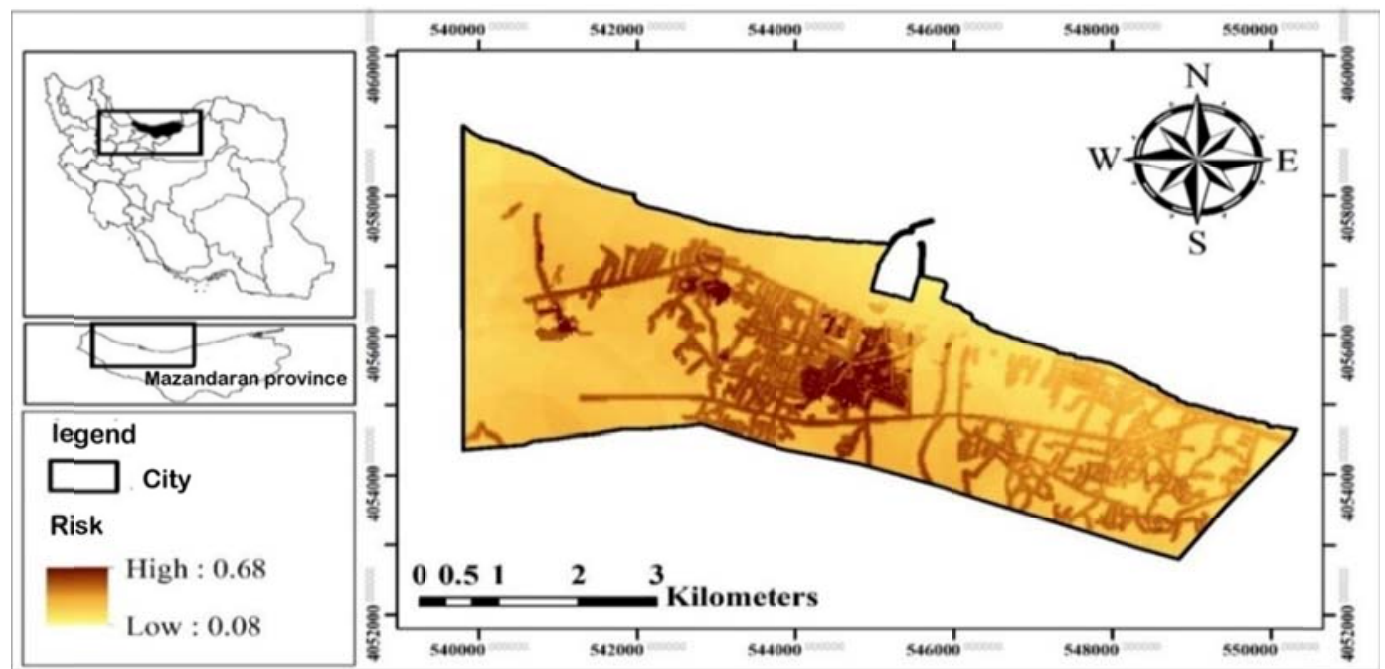

Figure 11. Fuzzy index map of earthquake risk in Nowshahr city

develop a comprehensive approach to be able to estimate the amount of risk and crisis, which requires the use of various specialties, including port city planning. The establishment of this relationship acts as a tool in reducing the vulnerability of cities and developing programs and policies to reduce damage. In such a case, based on a rationalist approach and using of different criteria in macro and micro scales, it would be possible to combine complex, multidimensional variables and quantitative and qualitative criteria to achieve a logical result. In this process, evaluation is performed by identifying the criteria that affect a system.

In this study, the earthquake risk model of Nowshahr city was prepared by Wisner and FAHP methods. One of the advantages of the proposed model is providing the possibility of simultaneous modeling of qualitative and quantitative information using MCDM systems (fuzzy technique and AHP) and GIS. In most available articles (10-13) one dimension of risk, vulnerability, and a small number of criteria is investigated; however, in this study, both dimensions of risk (i.e., being at risk and vulnerability) were evaluated using Equation 1.

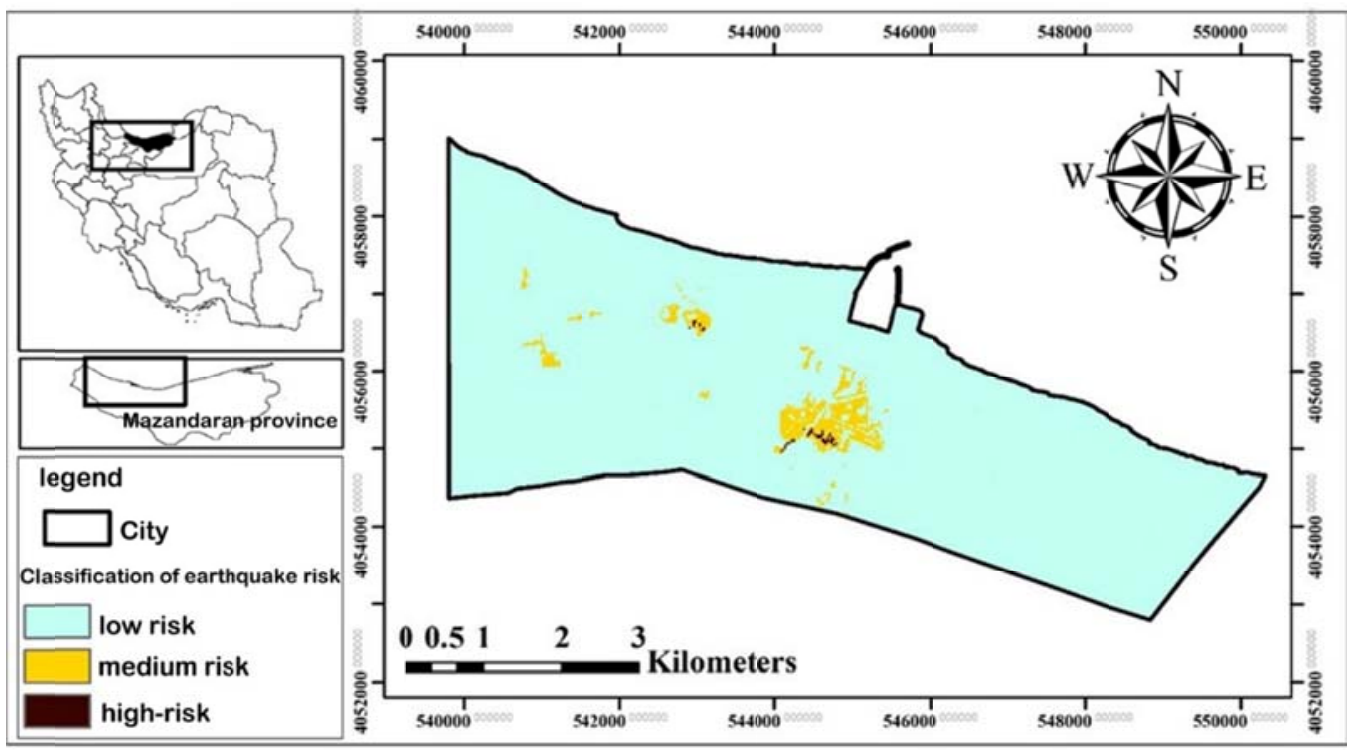

Figure 12. Classification of earthquake risk map in Nowshahr city 
In the earthquake risk assessment model, the studied area was evaluated based on a combination of risk and urban vulnerability, and earthquake risk and vulnerability were assessed according to different components in the port city of Nowshahr. Afterward, the earthquake risk map of Nowshahr city was prepared in two forms of fuzzy (Figure 11) and stratified (Figure 12) by combining the two maps of risk and vulnerability maps. Based on the results, about $97.13 \%$ (2,810.296 ha), $2.75 \%$ (79.567 ha), and $0.12 \%$ (3.441 ha) of Nowshahr city were in low, medium, and high-risk categories, respectively. It was also revealed that high-risk earthquake areas were mainly located in the city center.

In general, it can be said that the central region of Nowshahr city is at a moderate to high risk at times of earthquake, highlighting the urgent priority of planning regarding the urban settlement improvement and urban space organization in that region. In the port city of Nowshahr, in areas where there is a high probability of earthquake incidence, most of the central part, is located the urban wornout texture. These areas are in a highly unfavorable situation, both in terms of spatial location and construction and urban planning, and lack the necessary standards of construction and urban planning. Gas supply and transmission lines are located in this area and the population density has exceeded the standard level; moreover, heavy traffic has disrupted transportation.

Due to the growing trend of Nowshahr city and port facilities and infrastructures (expansion of communication networks and infrastructures of Nowshahr city), non-observance of the most basic safety rules in urban constructions, lack of planning for the city growth and development, and unsustainable port development have caused a lot of damage in the event of an earthquake. Therefore, the following recommendations are given to prevent the occurrence of tragedy and irreparable damage or minimize it:

-The need for paying attention to and planning for infrastructure in relation to high-risk areas and preparing a special organizing plan for the emergency settlement area located in the east of the city and north of the road next to the city of Nowshahr.

-Adopting preventive and management measures in times of crisis in high-risk areas and prepare a special plan (urban design) for the center of Nowshahr city as a privileged and upgradeable urban space.

It is also suggested that with proper planning and management, the process of improvement and renovation of worn-out textures be taken into consideration and their rehabilitation be a priority on the agenda.

\section{Acknowledgments}

None

\section{Conflict of Interests}

Authors have no conflict of interests.

\section{References}

1. Adger WN, Hodbod J. Ecological and social resilience. Handbook of sustainable development. Cheltenham: Edward Elgar Publishing; 2014.

2. Khan H, Khan A. Natural hazards and disaster management in Pakistan. Peshawar: Munich Personal RePEc Archive; 2008.

3. Yazdanfar C. Structural analysis of Piranshahr fault as the Northeast part of Zagros main resent fault by using DTM model and GIS. Geograph Res 2014; 29(4): 139-53 (In Persian).

4. D'Albe EF. An approach to earthquake risk management. Eng Struct 1982; 4(3): 147-52.

5. United Nations Development Programme. Bureau for crisis prevention. Reducing disaster risk: a challenge for development-a global report. New York: United Nations Development Programmed; 2004. P. 1-146.

6. Mohapatra AK, Mohanty WK, Verma AK. Estimation of maximum magnitude ( $\mathrm{M}$ max): Impending large earthquakes in northeast region, India. J Geolog Soc India 2014; 83(6): 635-40.

7. Asian Disaster Preparedness Center. Communitybased disaster risk management. United Nations economic and social commission for Asia and Pacific (UNESCAP) and European commission humanitarian aid department (ECHO). Bangkok: Asian Disaster Preparedness Center; 2008.

8. Mansouri N, Nazari R, Nasiri P, Gharagoozloo A. Planning forest fire crisis management using GIS \& RS. J GIS RS Appl Plann 2011; 2(3): 63-73 (In Persian).

9. Abedini M, Sarmasti N. Seismic power of Tabriz fault and casualties in Tabriz metropolitan assessment by experimental models and GIS. J Geography Earth Sci 2016; 4(1): 31-45 (In Persian).

10. Lantada N, Pujades LG, Barbat AH. Vulnerability index and capacity spectrum based methods for urban seismic risk evaluation. A comparison. Natural Hazards 2009; 51(3): 501.

11. Pourmohammadi M, Karami M. Integration of 
Kernel model (KDE) and AHP model in order to evaluate the earthquake risk in urban squatter and timeworn textures by geographic information system (GIS) a case study in Tabriz (municipal areas No. 1 \& 5). Geography Plann 2015; 18(50): 55-88 (In Persian).

12. Shamai A, Heidarzadeh N, Lotfi Moghadam B. Analysis of earthquake deleterious factors in Tehran's district 1 using GIS. Geography Plann 2013; 17(43): 93-122 (In Persian).

13. Alizadeh F, Afsari N, Taghizadeh Farahmand F. Evaluation of deterministic seismic hazard in Nowshahr Port by using fuzzy system. J Natl Environ Hazards 2019; 8(19): 175-94 (In Persian).

14. Statistical center of Iran. Available at: URL: https://www.amar.org.ir/english; 2011. [In Persian].

15. Wisner B, Blaikie P, Blaikie PM, Cannon T, Davis I. At risk: natural hazards, people's vulnerability and disasters. London: Psychology Press; 2004.

16. Dehghani Filabadi A. Consensus modeling in Delphi's process using the concept of qualitative reasoning and its application in identification and localization effective criterions to improve the quality of services. Modern Res Decision Mak 2019; 3(4): 104-24(In Persian).

17. Salehnasab A, Feghi J, Danekar A, Sousani J, Dastranj A. Forest park site selection based on a Fuzzy analytic hierarchy process framework (Case study: the Galegol Basin, Lorestan province, Iran). J Forest Sci 2016; 62(6): 253-63 (In Persian).

18. Jinzhi FA, Deyong GU, Jianguo ZH. Analytic hierarchy process determining weights of factors influencing coal and gas outburst. Mining Saf Environ Protect 2004; 31(3): 4-5.

19. Celik M, Er ID, Ozok AF. Application of fuzzy extended AHP methodology on shipping registry selection: the case of Turkish maritime industry. Expert Syst Appl 2009; 36(1): 190-8.

20. Gumus AT. Evaluation of hazardous waste transportation firms by using a two-step fuzzy-AHP and TOPSIS methodology. Exp Syst Appl 2009; 36(2): 4067-74.

21. Malczewski J. On the use of weighted linear combination method in GIS: common and best practice approaches. Transactions GIS 2000; 4(1): $5-22$. 